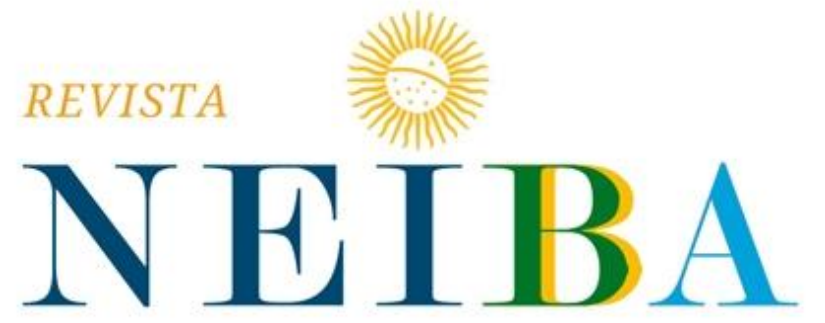

CADERNOS ARGENTINA-BRASIL

\title{
ENTRE LA PAMPA Y EL MAR: SARMIENTO, HERNÁNDEZ E UM BOSQUEJO HISTÓRICO-LITERÁRIO SOBRE A GÊNESE DO PENSAMENTO GEOPOLÍTICO ARGENTINO
}

\author{
BETWEEN LA PAMPA AND THE SEA: SARMIENTO, HERNÁNDEZ AND A BRIEF \\ HISTORICAL-LITERARY NOTE ON THE GENESIS OF ARGENTINE \\ GEOPOLITICAL THINKING
}

\section{Gabriel Rodrigues Peixoto ${ }^{1}$}

${ }^{1}$ Universidade Federal da Integração Latino-americana (UNILA), Foz do Iguaçu, PR, Brasil. E-mail: rodriguespeixoto@mail.ru ORCID: https://orcid.org/0000-0001-7438$\underline{0788}$

Recebido em: 26/10/2020 | Aceito em: 04/01/2021. 


\section{RESUMO}

A dialética histórica entre forças telúricas e talassocráticas teve clara manifestação no desenvolvimento bifurcado do pensamento geopolítico argentino no século XX. É certo afirmar que em suas elucubrações conceituais, com vistas a reafirmar a dialética de raiz mackinderiana na realidade nacional, tal antinomia, ainda que inevitavelmente influenciada por autores estrangeiros, recorreu a um imaginário de arraigo às renhidas disputas que marcaram o processo de fundação do país. Aqui, não por um acaso, aquelas obras consideradas símbolos na construção do ideário político da república, Facundo: Civilización y Barbarie e Martin Fierro, haveriam de estar invocadas recorrentemente na produção teórica da geopolítica local. É nesse sentido, que este artigo parte a identificar, desde uma análise histórico-literária, as correspectividades mitopolitológicas entre as obras de Domingo Sarmiento e José Hernández e aqueles aspectos próprios do enfrentamento primordial entre aquelas forças da terra e do mar que lastreiam o pensamento geopolítico.

Palavras-chave: Pensamento geopolítico, Literatura, Argentina.

\section{ABSTRACT}

The historical dialectics between telluric and thalassocratic forces was clearly manifested in the bifurcated development of Argentine geopolitical thought in the 20th century. It is true to say that in its conceptual elaborations, in order to reaffirm the Mackinderian dialectic in the national reality, such antinomy, although inevitably influenced by foreign authors, resorted to a deep-seated imagination of the fierce disputes that marked the country's founding process. Here, not by chance, those works considered symbols in the construction of the republic's political ideology, Facundo: Civilización y Barbarie and Martin Fierro, would be repeatedly invoked in the theoretical production of local geopolitics. It is in this sense that this article sets out to identify, from a historical-literary analysis, the mythopolitological correlations between the works of Domingo Sarmiento and José Hernández and those aspects of the primordial confrontation between those forces of land and sea that support geopolitical thought. Keywords: Geopolitical thinking, Literature, Argentina. 


\section{INTRODUÇÃO: ENTRE A TERRA E O MAR}

Carl Schmitt (1942) arrazoava que a história mundial seria aquela da antinomia entre potências marítimas e continentais, se tratando todas as guerras em verdade de capítulos de um conflito eterno, resultante da dialética primordial e imutável entre aquelas forças do tempo-mar e da eternidade-terra. Nesse enfrentamento, aquelas zonas onde preponderam os poderes do mar, representantes da técnica separada de todas as normas da tradição, dariam lugar ao aparecimento de sociedades caracterizadas por um etos de tipo cosmopolita e democrático, ligados à natureza comercial. Em seu oposto polar, aquelas civilizações continentais, que se depositam principalmente em seus respectivos heartlands, partilhariam de características não comerciais, autoritárias, hierárquicas e antidemocráticas, carregando em si mesmas uma ordem que lhes é autóctone (Dugin, 1997; Nad, 2016).

Para se confirmar como geopolítica, tal dialética histórica, plasmada no pensamento mackinderiano ${ }^{2}$, não poderia deixar incólumes quaisquer rincões. E em poucos lugares essa se manifestou de maneira tão radical como na Argentina. Desde sua gênese, as encarniçadas guerras civis platinas (1814-1880) colocaram enfrentados os bandos unitários, alocados na cidade-porto Buenos Aires, e federal, entrincheirado no interior do país. Num impasse incapaz de ser resolvido a nível local, tal antinomia acabou por impedir a gênese de uma consciência unificada a respeito dos objetivos nacionais do nascente país, deixando marcas indeléveis na política nacional (Fávaro Martins, 2016).

Para Methol Ferré (1961), o golpe perpetrado pela Junta de Mayo de 1810 contra a autoridade vice-real colonial já encarnava em seu âmago as pretensões da elite de Buenos Aires conformada por “(...) una clase dominante en la que se unen la oligarquía de terratenientes corambreros, la burguesía intermediaria que comercia de exportación e importación" (Trias, 1975, p. 8) que visava transformar o país em uma "(...) espécie de colonia informal de Gran Bretaña, el llamado quinto dominio, ocupando una posición de dependencia para la cual, no existía paralelo exacto fuera del imperio" (Moniz Bandeira,

\footnotetext{
${ }^{2} \mathrm{~A}$ visão mackinderiana baseia-se no condicionamento geográfico dos processos históricos em uma sorte de dialética resultante da confrontação entre potências oceânicas e potências continentais, com proeminência - em última instância - destas últimas (Mello, 1999, p. 34).
} 
2004, p. 545). Sem as amarras da estrutura do poder colonial, a elite estacionada na cidade-porto poderia se livrar de suas amarras em relação ao restante do território do vice-reinado e consolidar o seu próprio poder.

Para o núcleo intelectual que daria gênese ao bando unitário, o porto e as rendas aduaneiras eram de patrimônio exclusivo da província que abrigava a capital, que se posicionava em uma localização geográfica estratégica que lhe conferia capacidade de cerrar o acesso ao Atlântico a todos os portos fluviais da Bacia do Prata. Nesse momento, o impulso centralista baseado no iluminismo europeísta age como força centrífuga para todo o alheio às vontades da cidade porto. O vasto território das Províncias do Prata e seus habitantes se tornam um problema de ordem maior, que deve ser enfrentado de maneira sistemática (Fávaro Martins, 2016).

O domínio bonaerense sobre as elites interioranas e a totalidade da economia da bacia do Prata entrava em contradição direta com as configurações de poder que se erigiam no interior. Profundamente contraposto desde sua gênese ${ }^{3}$ ao weltanschauung unitário, o ideário federal habitava uma aproximação distinta a modernidade, oposta ao modelo econômico e civilizacional atrelados centrados na hegemonia inglesa, das quais a burguesia compradora portenha era apêndice econômico e ideologicamente tributária. Se estes representavam o poder marítimo e a insularização do país, aqueles tinham numa estratégia continentalista o centro de seu projeto de poder:

El Imperio Español generó, a través de varios siglos, fuerzas unificadoras, centrípetas, que contribuyen a explicar la idea de una nación continental, Instituciones comunes, religión, cultura e idiomas comunes, el sentimiento de pertenecer a un vasto Estado nacional. Pese a que algunos de esos factores fueron quebrantados por la revolución, sirvieron de punto de partida a nuevas fuerzas unificadoras derivadas de la guerra por la independencia (Trias, 1978, p. 2).

Shumway (2008) se utiliza do termo fiç̧ões-diretrizes para tipificar as correntes de pensamento idealizados por diferentes pensadores e em distintas épocas ao longo do processo de construção da identidade na Argentina, tendo por referência a Alberdi (1913), para quem a nação estaria dividida pela "noção de dois países, duas sociedades,

\footnotetext{
${ }^{3}$ Desde sua gênese, irrompe no bando federal uma estratégia político-territorial arraigada em um modelo federativo que visava por manter a autonomia das províncias tal como os arranjos políticos locais. A Liga de los Pueblos Libres tinha por entendido que a manutenção da grandeza territorial de - ao menos - o vice-reinado do Prata era sustém principal da independência da nação que se construía, pelo qual cobra também centralidade a questão econômica com uma concepção americana de desenvolvimento (Cabral, 2013, p. 197).
} 
dois desenvolvimentos paralelos, duas histórias" (Alberdi apud Shumway, 2008, p. $286)^{4}$.

Para duas histórias, duas escrituras: tanto a obra El Gaucho Martín Fierro (1872) quanto Facundo o civilización y barbarie en las pampas argentinas (1845), consideradas obras-símbolo da constituição da República Argentina, teriam sido preponderantes a moldar tais ficções diretrizes, corroborando a uma mitologia nacional lastro na construção da argentinidade. Nelas, se de um lado temos a Hernández avançando a um arranjo federalista de maior autonomia do interior, do outro temos a Sarmiento escorado nas ideias dum centralismo espelhado no Velho Continente. Em ambas se aprecia tanto "um esquema de propaganda governamental quanto fornecedor de um arcabouço de tradições culturais" à incipiente nação (Minelli, 2013).

Dito isto, há de reter que no centro mesmo da discussão abarcada em ambas as obras, revela-se um enfrentamento centrado acerca de concepções arquetípicas sobre onde repousariam as fronteiras das Províncias do Prata, que irrompem enquanto demarcadoras de espaços desde óticas distintas acerca de seus sentidos sociais. O mesmo hinterland seria interpretado tanto como albergador de fronteiras internas a serem desativadas quanto como território emanador de possibilidades telúricas. As fronteiras externas, da mesma maneira, seriam enfocadas tanto como elemento de encerramento e insularização frente ao oceano de atraso ofensivo representado pela geografia continental, ou como possibilitadoras de uma ordenação de um futuro grande espaço geo-político.

Aqui, não por acaso, se tratando as duas obras, a seu próprio modo, de expressões culminantes da literatura gauchesca (Altamirano, 2001), a figura do gaucho acabou por ocupar lugar central, tomando protagonismo na discussão intelectual que disputava a hegemonia sobre o dever-ser da todavia infante Argentina do século XIX. Percebido como personagem chave dos conflitos que se espalharam sobre o território da nação, este modo de ser híbrido ${ }^{5}$ haveria de habitar as obras de Sarmiento e Hernández já fosse como um epifenômeno do atraso enfrentado ao avanço civilizacional, na primeira,

\footnotetext{
${ }^{4}$ Alberdi afirmava que a relação entre Buenos Aires e as demais províncias se tratavam em verdade de uma vinculação de ocupação, já que se tratavam de fato de países distintos (Alberdi, 1886, p. 329).

${ }^{5}$ Tendo por referência os conceitos de Canclini (2001; 2004) e Dalle (2010).
} 
ou como receptáculo actancial das possibilidades de uma civilização idiossincrática na última (Ramos, 1989; Minelli, 2010).

Em ambos os casos, dimana um significado pedagógico próprio do mito, em que a "linguagem não é informativa nem comunicativa, não é comunicação de informação, mas (...) transmissão de palavras de ordem" (Deleuze; Guattari, 1995, p. 12). Aqui, a carga política envolta a tal construção de ordem mitológica se desprende não de qualquer pretensão de autenticidade, mas, todavia, de pretender-se a verossimilhança. Trata-se, portanto, da manifestação histórica de forças sociais concretas que podem ser rastreadas pela análise da mesma linguagem e que estão para além de seus autores enquanto indivíduos (Lillo, 2018).

Dito isso, e ao que aqui nos interessa, é certo dizer que também o campo do pensamento geopolítico argentino, reforçado ademais pela narrativa dicotômica entre terra e mar, se viu tributário da dualidade entre a tendencial liberal de insularização do país e ao reavivamento da tradição federal em uma racional estratégica de corte regional (Fávaro Martins, 2016; Trias, 1978; Pedraza, 2009). Por tal razão, bem como nos remarca afirma Rizzo Romano (1973), jamais foi possível falar de uma Escola Geopolítica na República Argentina.

Vale remarcar que nas mesmas origens do pensamento geopolítico sul-americano figura o Vice-almirante da Armada, Segundo Rosa Storni (1876-1954), quem assumiu por verdadeira a dialética geofilosófica entre forças telurocêntricas e talassocêntricas ${ }^{6}$, sendo ferrenho defensor da proeminência desta última na esteira do pensamento mahaniano7. Todavia, em suas elucubrações, Storni tinha como central em seu pensamento uma sorte de "darwinismo antropológico" lastreado numa racional histórico-geográfica de influência sarmientiana (Garré, 2009, p. 8). Ademais, Storni haveria de colocar as novas teorias geopolíticas recém chegadas de latitudes setentrionais a serviço dum imaginário político de corte liberal, na esteira do unitarismo

\footnotetext{
${ }^{6}$ Derivado do grego tellus, significado por terra, seria telurocrática uma civilização cujo poder estivesse baseado principalmente no seu vasto domínio territorial terrestre concentrado numa área continental; por sua vez, uma civilização talassocrática, derivada do grego thalassa - mar -, seria aquela lastreada em sua expansão marítima, tendente ao espalhamento de sua influência em territórios não-contíguos e, especialmente, voltada a atividade comercial.

7 Alfred Mahan (1840-1914) foi o teórico que mais profundamente influenciou a teoria da proeminência do poder marítimo, englobando a aspectos político-econômicos, geopolíticos, psicossociais e militares, restando especial importância a preponderância do mar no desenvolvimento econômico de uma nação (Monteiro, 2013).
} 
do século XIX, baseado no tripé da primazia da cidade-porto sobre o hinterland, do modelo agroexportador e da reafirmação da Argentina um lugar de pertencimento coadjuvante nos limites do imperialismo anglo-saxão (Guglialmelli, 1979).

Em sua antípoda, se bem o desenlace de $\operatorname{Caseros}^{8}$ significara a fundação de uma república a imagem e semelhança da sanha liberal unitária, esse jamais pôde dar cabo em definitivo a influência do pensamento federal sobre larga parte da intelectualidade e do imaginário político da população local (Fávaro Martins, 2016). Como resultado, a mitologia federal do século XIX, haveria de cobrar centralidade na gestação do pensamento nacionalista argentino da primeira metade do século $X X$, sendo referente na crítica filosófica própria da apropriação peronista (Casas, 2020) que haveria de tornar-se igualmente numa racional geopolítica, como nos trabalhos de Astrada ${ }^{9}$ e Jauretche ${ }^{10}$, que jamais se denegaram a referir-se à obra de José Hernández.

Tendo por conta o acima descrito, cremos ser pertinente identificar, ainda que aqui o façamos de maneira incipiente, aqueles aspectos de corte geopolítico contidos nos ideários políticos unitário e federal do século XIX plasmados nas obras de Sarmiento e Hernández. Nesse sentido, tomamos como referência as obras de Kaplan (2014), Boyagoda (2016), Howell (2016) e Goyal (2017) as quais já fizeram aproximações similares entre o nexo entre literatura e geopolítica em países específicos.

Necessário é reter, entretanto, que partimos da hipótese de que já estavam dadas, em ambas as obras aqui esmiuçadas, elementos que advém da mesma dialética geopolítica primordial a qual se refere Schmitt, ainda que as mesmas tenham sido publicadas antes mesmo de que a geopolítica tenha sido sistematizada enquanto disciplina. Cremos que tal fato deu ampla sustentação para que as narrativas geopolíticas do século $\mathrm{XX}$, divididas primordialmente e tal como supracitado, em aproximações teluro e talassocráticas, encontrassem ampla ressonância em seu desenvolvimento nas margens do Rio da Prata, a primeira amplamente avançada por grupos nacionalistas e a segunda sendo propugnada por frações liberais.

\footnotetext{
${ }^{8}$ Em referência a Batalha de Monte Caseros, em 1852.

9 Ver: Astrada, C. (1948). El mito gaucho. Martín Fierro y el hombre argentino. Buenos Aires: Cruz del Sur.

10 Ver: Cangiano, G. (2001). 'El pensamiento vivo de Arturo Jauretche', In: Cangiano, G Nuevos Aportes sobre Arturo Jauretche. Buenos Aires: Archivo y Museo Históricos de la Provincia.
} 
Dito isso, lançaremos mão nas próximas páginas de uma análise históricoliterária, sem perder de vistas os contextos em que essas foram concebidas e tendo em conta a posição de que o mito não se trata de ideação arbitrária mas expressão visível do que subjace ${ }^{11}$.

\section{EL SOÑADOR SIGUE SOÑÁNDONOS}

Dizia Jorge Luis Borges (2007) que "Sarmiento el soñador sigue soñándonos" (p. 208). E por certo, a mesma fundação da República Argentina seria culminação erigida principalmente - ao redor do ideário plasmado na obra do talvez maior intelectual do bando unitário, Domingo Faustino Sarmiento (1811-1888), tendo sua máxima expressão no panfleto batizado de "Facundo o civilización y barbarie en las pampas argentinas" (1845).

Escrita durante seu degredo no Chile, e publicada pela primeira vez nas páginas do periódico El Progreso, de sua propriedade, a obra haveria de ser posteriormente organizada em livro com a adição de seus dois capítulos finais. Dividida em três partes, a obra debuta arrazoando uma descrição de corte geográfico, que se emaranha pelo antropológico, enquanto coloca suas vistas sobre costumes e tradições locais do hinterland argentino, aludindo a tarefa de biografar ao caudillo riojano Facundo Quiroga, morto em Córdoba em 1835, e tendo por central os desdobramentos da guerra civil entre unitarios e federales. Em sua derradeira seção segmentada em dois capítulos escritos como adendos, finalmente esboça um projeto civilizatório, erigido ao redor de um programa liberal para uma nova nação devenida duma inevitável futura queda de Rosas.

Interessante é notar que mesmo tendo por alvo o governo de Juan Manuel de Rosas, Sarmiento é incapaz de avançar sobre o maior dos caudilhos federais em seu panfleto. Tal como nos recorda Borges, a essa altura "Rosas no le servía" em sua construção narrativa dado que além de se parecer pouco aos rústicos caudillos interioranos, "ofrecía el notorio inconveniente de no haber muerto". Tendo em vista dar cabo àquelas as subjetividades de carga mítica que se erigem ao redor do

\footnotetext{
${ }^{11}$ Ver: Evola, J. (1979). A Tradição Hermética. São Paulo: Edições 70.
} 
federalismo, restava-Ihe avançar sobre uma figura de tipo prototipal, encarnadora da idiossincrasia dos pagos do hinterland argentino e que tivesse sido vítima de um destino um tanto mais trágico: o riojano Quiroga desponta em protagonista porque ademais de carregar dentro de si tudo aquilo que Sarmiento rejeita, tem por ato derradeiro morrer “acribillado y apuñalado en una galera" (Borges, 1998, p. 209).

Nessa mesma direção, a pampa como berço de caudilhos e criadouro das hordas de gauchos que os seguem, é subjetivada como território hostil que carrega em si os causantes do enfrentamento que arrebata o país. Sarmiento tinha por certo que a dicotomia que dividia o país era ditada antes que nada pela geografia que determinava suas discrepâncias culturais afirmando que "Rosas y Rivadavia son los dos extremos de la República Argentina, que se liga a los salvajes, por la pampa y a la Europa, por el Plata" (Sarmiento, 1999, p. 114).

Por esta razão, sua obra se dá em termos geográficos e dela desponta uma visão estratégica que dá significado e sentido próprio ao espaço (Pickenhayn, 2000). Existe uma clara urgência de reordenamento territorial atrelado a uma escolha civilizacional aderida a um modelo econômico-produtivo sobre a sombra do que considera como irradiador civilizacional superior, o mundo anglo-saxão. Caso assim não o fosse, as Províncias do Prata estariam inexoravelmente destinadas ao não-progresso por conta do tripé que considera reunir a fórmula perfeita do atraso: raça, herança espanhola e terra (Shumway, 2008).

Sob influência iluminista, principalmente aquelas de Rousseau e Montesquieu, tinha por entendido que as melhores práticas democráticas estavam dadas naqueles países de território diminuto, sendo a própria extensão territorial das Províncias do Prata um problema de ordem fundamental (Fávaro Martins, 2016). Ao seu julgar, "[e]l mal que aqueja la República Argentina es la extensión: el desierto la rodea por todas partes, y se le insinúa en las entrañas; la soledad, el despoblado sin una habitación humana" (Sarmiento, 1999, p. 21).

Enfrentadas em dualidade, a pampa aparece como o inverso espaço-temporal da urbe referencial europeia. O campo dá lugar a uma cultura que habita o limiar da civilização. Como num devenir que lança o título da obra numa sorte de deformação, 
Civilización o Barbarie, calcada numa pretensa dicotomia travada entre um hinterland esparsamente povoado por bárbaros e uma elite entrincheirada e portadora de uma missão civilizatória. A barbárie, representação mesma do primitivo, é o atraso temporal que há de ser superado:

Es preciso conocer al gaucho argentino y sus propensiones innatas, sus hábitos inveterados. Si andando en la pampa le vais proponiendo darle una estancia con ganados que lo hagan rico propietario; si corre en busca de la médica de los alrededores para que salve a su madre, a su esposa querida que deja agonizando, y se atraviesa un avestruz por su paso, echará a correr detrás de él, olvidando la fortuna que le ofrecéis, la esposa o la madre moribunda; y no es él solo el que está dominado de ese instinto; el caballo mismo relincha, sacude la cabeza y tasca el freno por volar detrás del avestruz (Sarmiento, 1999, p. 222).

Aqui, o gaucho enraizado a própria paisagem a qual habita, aparece como esfinge contraposta ao homem civilizado pertencente às nações desenvolvidas. Retirando-Ihes quaisquer traços de europeidade, Sarmiento lança a noção de que a descendência civilizacional ibérica se trata em verdade de um traço indesejado, ligado ao atraso (Escolar, 2011):

[Sarmiento] definió que "civilización" era el idioma inglés y, "barbarie" el castellano. "Barbarie" era, para "el Maestro de "América", todo lo autóctono, por el solo hecho de serlo y, por supuesto - y he ahí el punto que más le interesaba a Inglaterra- "civilización" era la aceptación a rajatabla de la teoría del liberalismo económico salvaje y del libre cambio absoluto (Gullo, 2011).

Posteriormente em Argirópolis (1850), Sarmiento avançaria o ideário exposto em Facundo, num intento de diagnóstico e projeto de poder, dando centralidade ao findar da guerra e a deixar "definitivamente constituídos aquellos países", em referência também ao vizinhos Paraguai e o Uruguai, dando uma dimensão estratégica aos territórios vizinhos em seu projeto de pacificação interna (Sarmiento, 2000, p. 14). Certo é que em referida obra, Sarmiento intenta romper com uma aproximação calcada em um determinismo geográfico, elencando uma sorte de subjetivação histórica com maior ênfase a ação de grandes homens em sua construção. Todavia, tal aproximação não lastreia qualquer ponto de inflexão em sua racional, ao contrário, apenas serve para reiterar a necessidade da ação de homens esclarecidos, obviamente aderentes ao seu próprio bando histórico, frente às condições histórico-geográficas percebidas por adversas. 
AL SALVAJE DE LAS PAMPAS QUE VOMITÓ EL INFIERNO, NI TUS HUESOS LA AMÉRICA TENDRÁ12

A eventual derrota de Rosas ante a coalizão de tropas unitárias e brasileiras na Batalha de Caseros, em 1852, abriu passo para a tomada de poder e eventual apossamento de uma hegemonia liberal-unitária na segunda metade do século XIX, no que haveria de tornar-se um encarniçado processo de unificação nacional erigido ao redor da fundação duma República Argentina, baixo um poder centralizador (Fávaro Martins, 2016). Os unitários não se fariam esperar em assentar as diretrizes de sua nova república, plasmando o leitmotiv dicotômico que nortearia o país no que se convencionou a chamar de Etapa de Organização Nacional (1852-1880).

Ascendia ao poder uma elite intelectual - adentrada a história como Generación del' 37 - até então proscrita e parcialmente exilada, que tinha por referência os desdobramentos políticos da Europa, carregando por ideal o afastamento da herança política espanhola e apregoando uma educação pública, laica e obrigatória, a imigração massiva como maneira de civilizar a pampa e, principalmente, a centralização da vida político-intelectual do país na cidade-porto de Buenos Aires:

La Generación del '37 se propuso construir una nación retomando el espíritu modernizante de la Revolución de Mayo pero incorporando los aportes del movimiento romántico europeo. (...) la mirada estaba puesta en Europa: faro del progreso y meta a alcanzar. En su diagnóstico el país era un desierto y había que hacer de él una nación moderna y civilizada (Dalle, 2008, p. 199).

A constituição de 1853, todavia carta magna do país e àquela altura considerada "la más liberal del mundo" (Abeille, 1901, p. 20-21), haveria de ser redigida pelo então ferrenho liberal Juan Bautista Alberdi, que naquela altura - já que haveria de arrepender-se anos mais tarde - defendia que a nova república deveria, antes que nada, ter um baixo perfil aduaneiro, aberta ao investimento estrangeiro e a imigração europeia (Alberdi, 1913; Fávaro Martins, 2016).

Da mesma maneira, tão logo iniciado o período das presidências históricas de Bartolomé Mitre (1862-1868), Domingo Faustino Sarmiento (1868-1874) e Nicolás Avellaneda (1874-1880) o centralismo se lançou à tarefa de solidificação da união nacional e a invenção de uma identidade nacional. Por objetivo estava desmontar a

12 Em referência ao poema "A Rosas", de José Mármol (1843). 
partir de uma historiografia oficial quaisquer dissidências e justificar historicamente o projeto liberal de nação (Quattrocchi-Woisson, 1995).

Não estranhamente, houve um resgate de mitos ligados aos heróis portenhos da independência com vistas em invisibilizar o federalismo. Irrompe uma "narração que não consegue ocupar plenamente o âmbito nacional (...); antes de ser da República Argentina, sua história é a dessa que López chama de burguesia liberal portenha" (Donghi, 1994, p. 199-200):

Por el mesianismo invertido, la mentalidad colonial cree que todo lo autóctono es negativo y todo lo ajeno positivo. Por el ideologismo porque prefiere manejar la abstracción conceptual y no la concreta realidad circunstanciada (Mastrorilli apud Jauretche, 1968, p. 9).

A elite da cidade-porto, certificando-se de que todos os seus inimigos fossem fisicamente derrotados, empenhou-se numa tarefa de limpeza que se lastreou na negação do heartland platino tal como na negação de suas expressões políticas autóctones e com a mesmíssima história platina. Emulando a ruptura com o Antigo Regime na Europa, a nova república se lançou à tarefa de criar aos argentinos que já não poderiam ser os que ali habitavam. Um acelerado processo de urbanização foi deflagrado aliado a um sistema de educação universal, público e obrigatório, imposto com o intuito de inculcar um novo espírito de pertencimento ao passo que que disseminava à cidadania o alerta sobre o impulso expansivo dos países vizinhos (Quintero, 1999).

Ante tal avanço sistemático, a redução do gaucho à condição peão de estância não se daria sem conflitos. Aqueles que se denegavam a aceitar a subjugação do bando no poder passaram a ser vítimas da sistemática violência do poder central: aqueles últimos caudillos federais seriam caçados pelo interior do país ${ }^{13}$ e, diferentemente da trágica morte de Quiroga retratada em Civilización y Barbarie, agora era o porto que ditava diretamente a vida e a morte na pampa (Fontana, 2011).

Nesse movimento de ação histórica contra a mesma geografia, a ocupação e

\footnotetext{
13 Talvez maior exemplo tenha sido o destino do general Ángel Vicente Peñaloza, El Chacho, quem no ano de 1863, após derrota na batalha Caucete, foi "rematado a tiros de carabina y mutilado. A su cadáver se le amputó una oreja y le cercenaron la cabeza, que fue exhibida durante ocho días en una plaza" (Cutolo, 1978. p. 405). Sarmiento (2010) haveria também de dedicar uma obra a Peñaloza, conhecida por 'El Chacho, último caudillo de la montonera de los Llanos (1868)'.
} 
consequente interiorização do Estado se apresentou como um mal menor. Procedeu-se a uma série de campanhas militares com fins de constranger a população autóctone e seus costumes, num processo que cobrou centralidade na tarefa disciplinadora do centralismo (Ludmer, 2002; Escola, 2011). Ademais, estando os mesmos gauchos adentrados ao exército, eram estes retirados do seu próprio pago e tinham suas idiossincrasias culturais reprimidas.

$\mathrm{Na}$ fronteira norte, irromperia uma guerra de proporções singulares com miradas postas sobre os resquícios do federalismo. A Guerra contra o Paraguai se desata como ação preventiva com vistas a impossibilitar qualquer aliança entre os governadores provinciais do Norte e Asunción contra o poder bonaerense (Shumway, 2008). Em movimento paralelo a presidência de Mitre se aproveita da guerra para "atacar a base de poder dos caudilhos reunindo gauchos para lutar contra os paraguaios, em um arranjo no qual dois grupos sociais inconvenientes se destruíram mutuamente" (Hernández, 1944

p. 84).

Rematado o conflito no Paraguai, o poder central se viu desimpedido para levar a cabo seu avanço territorial até os rios Negro e Neuquén. Se desatava na fronteira sul a campanha alcunhada de Conquista del Desierto (1878-1885) liderada pelo general e posteriormente presidente, Julio Argentino Roca. Por objetivo estratégico estava securitizar a região patagônica ante as ameaças daqueles que já habitavam-na - os indígenas - tal como às pretensões chilenas sobre a região. Por essa lógica, as fronteiras externas se transformaram em fronteiras internas que deveriam ser desativadas. Além disso, o avanço territorial serviria para a expansão da fronteira agropecuária, calcada no binômio da mão de obra imigrante e agroexportação (Seixlack, 2012). Uma vez mais, o peito do gaucho haveria de ser fronteira duma república a qual não poderia pertencer.

\section{NO SOY DE AQUII, NI SOY DE ALLÁ (... $)^{14}$}

Shumway (2008) remarca que o centralismo unitário também se aproveitou da justificativa de enfrentamento a um inimigo externo para silenciar aquelas vozes intelectuais opositoras que todavia restavam em rebeldia. Entre elas, está presente a

\footnotetext{
${ }^{14}$ Em referência a canção pelo cantor e compositor argentino Facundo Cabral em 1970.
} 
figura de José Hernández, àquela altura exilado e quem jamais denegou sua aversão aos unitários:

Ele [Mitre] povoou de cadáveres nossos campos com sangrentas intervenções armadas; pisoteou a soberania das províncias com farisaicas intervenções pacíficas [..] sancionou o Tratado da Tríplice Aliança, contra as conveniências e contra o sentimento nacional; lançou o governo em uma guerra contra o Paraguai e por três anos permaneceu à frente do exército para demonstrar sua imperícia e incapacidade militares (Hernández, 1944, p. 83).

Sendo um "hombre de letras pero también de acción" (Crocco, 1995, p. 2), sua mocidade na pampa - sendo seu pai administrador de fazendas de Rosas - haveria de deixar marcas indeléveis em sua adultez (Gálvez, 1945; Borges, 1985, p. 32):

\begin{abstract}
La pampa es la principal escuela en la que se educa el muchacho. En ella cursó su bachillerato de poeta épico, de narrador de la vida campestre de su tiempo. Diez años pasa Hernández en aquellas estancias. No tiene mucho contacto con la ciudad. Cuando viene es por pocos días. No obstante su encariñamiento con el campo, él no se convierte en un gaucho. La barbarie de la pampa - si existe, según cree Sarmiento- no le barbariza. Abandona el campo a los 19 años, sin haber perdido su cultura (Gálvez, 1945).
\end{abstract}

Desde a década de 1850, pouco após a batalha de Caseros, Hernández esteve integrado às milícias montoneras ${ }^{15}$, havendo de lutar junto às tropas de José Justo de Urquiza em Entre Rios e, ao que nos parece significativo, estando presente também naquela última rebelião federal na chamada Rebelión Jordanista, desdobramento interno da Guerra contra o Paraguai e último episódio da larga guerra civil argentina, já na década de 1870.

Derrotado, exilado e finalmente perdoado pelo governo Sarmiento, haveria de voltar à Argentina onde seria deputado (1879-1881) e senador (1881-1886) pela Legislatura da Província de Buenos Aires, levando em paralelo, tal como o fizera durante toda sua vida, uma extensa e combativa carreira no periodismo onde profusamente haveria de igualmente seguir enfrentado a cidade-porto, a qual considerava haver surgido de uma "espécie de aristocracia à qual o interior abandonado paga tributo, assim como nos velhos tempos, antes da formação das sociedades modernas" (Hernández, 1944, p. 91).

Certo é, porém, que a obra que o faria entrar de forma definitiva na história argentina seria em verdade uma exceção em sua carreira (Minelli, 2010). Jamais

15 Montoneras eram unidades militares de extrato rural, encabeçadas por caudilhos regionais enfrentadas as milícias governamentais. 
conhecido por ser exatamente um poeta, foi justamente através de um largo poema, que haveria de expor de forma magistral suas próprias interpretações de parte do imaginário federal.

Certo modo, o gaucho e a gauchesca se impuseram à militância literária de Hernández, irrompendo "a literatura gauchesca e suas formas campesinas (...) como forma de diferenciar seu posicionamento político" daqueles de Sarmiento e seu bando (Minelli, 2010, p. 5). Não por acaso, seria a Conquista del Desierto o alvo de sua magnum opus.

Publicada em duas partes, El gaucho Martín Fierro (1872) e La vuelta de Martín Fierro (1879), a obra seria organizada posteriormente em apenas um livro. Permeada por ruralismos, esta se afasta da norma culta para adentrar-se de forma absoluta no hinterland argentino em sua arcana extensão, que irrompe como berço de uma idiossincrasia própria e percebida como lastro mesmo das possibilidades de um Ser argentino.

Em sua primeira seção, seu protagonista, acompanhado por seu amigo Cruz e um violão, relata as vicissitudes ante ao processo de Organização Nacional que the extrai de sua vida cotidiana e o transforma em soldado. Acuado pelo poder instituído e posto a combater numa guerra a qual não Ihe apetece, tem por única opção dar fuga de um território em que é considerado inimigo. Rumando ao além-fronteira, se embrenha na imensidão da pampa austral junto aos indígenas. Para o gaucho, esse se torna o espaçotemporal que lhe dá possibilidades de seguir sendo:

Yo sé que los caciques amparan a los cristianos, y que los tratan de "hermanos" Cuando se van por su gusto A qué andar pasando sustos... Alcemos el poncho y vamos (Hernández, 2009, p. 83).

Para Astrada (1948), em Martín Fierro está expressada a mesmíssima teluricidade argentina da qual emerge o mito que dá substrato ao numen da nacionalidade. O pago como lugar de unidade geopolítica está perpassado por uma elevada carga subjetiva não dimensionada pela mera objetividade econômica: naquelas dezoito vezes em que aparece ao longo do derrotero de Martín Fierro, a palavra está procedida por pronomes possessivos que remetem a mesma raiz latina da palavra, pagus, como lugar delimitado 
ao qual o ser entrava uma relação de pertencimento (Suárez, 2018). A errância irrompe como resposta a um Estado que ao retirar o espaço do homem do campo também lhe retira de seu próprio tempo histórico (Minelli, 2013).

Por certo, não raros são os trabalhos de literatura comparada que se lançam ao exercício de estabelecer pontes entre Martin Fierro e a magnum opus do espanhol Miguel de Cervantes, El ingenioso hidalgo Don Quixote de la Mancha ${ }^{16}$. Como nos comenta Ullivarri (2005), resulta impossível precisar se a obra de Hernández se vê influída diretamente pelas pegadas do alazão Rocinante em razão de leituras diretas de seu autor ou se o gaucho retratado no livro, descendente de espanhóis que pelas vicissitudes de seu tempo haviam cruzado o oceano, fora apenas retratado como portador dos trejeitos de um povo outrora observado por Cervantes. Ao que nos parece, esta se trata duma discussão menor. Importa dizer que se para Sarmiento a herança espanhola erigia uma das patas do tripé do atraso, em Martín Fierro a hispanidade, constitutiva do Ser gaucho, é exortada e alçada a lastro das possibilidades da argentinidade.

Finalmente, em La vuelta, Fierro, retornado de seu degredo no além-fronteira que já não o é, retoma a narrativa em ponderação ante a estranha burocracia que pretende moralizar o interior. Resignado, na fração derradeira da obra, parte a aconselhar aos seus para que busquem construir outra realidade mais justa, onde tais desgraças já não recaiam sobre o povo: "[l]os hermanos sean unidos, porque esa es la ley primera; tengan unión verdadera en cualquier tiempo que sea, porque si entre ellos pelean los devoran los de ajuera" (Sarmiento, 1999, p. 263).

\section{CONSIDERAÇÕES FINAIS}

Ao que nos parece, tanto Martín Fierro quanto Civilización y Barbarie, cobram vastíssima envergadura político-social ao plasmar em folheto os ideários políticos dos respectivos bandos aos quais pertenciam seus autores, se tornando pontos de partida para a análise da Argentina, sem que isso queira dizer que estes sejam pontos iniciais do país. É o mesmíssimo desenrolar histórico o que dá sustentação para que tais obras

\footnotetext{
16 Afirmava Casimiro Muñoz (1889) que "Martin Fierro es un eco de nuestra España del Siglo XII; aquellos gauchos son
} nuestros aventureros y el soplo (...) de nuestros primitivos romanceros" (Muñoz apud Unamuno, 1996, p. 56). 
resistissem ao escorrer do tempo cobrando ressonância pedagógica.

Por sua vez, ao que tange ao pensamento geopolítico argentino, tratar as influências do século XIX nas concepções estratégico-territoriais do país como meras apropriações de "ficções-diretrizes" seria incorrer em erro. Como podemos verificar, as obras de Sarmiento e Hernández irrompem como afloramento da dinâmica históricogeográfica do nascente país. A centralidade dum modo de ser tão profundamente enraizado e autóctone como medida ante o acesso à modernidade é, antes que nada, desveladora de racionais geográficas próprias aos dois principais bandos enfrentados na história do país. Os mitos apregoados ao redor do gaucho irrompem, sim, como pedagógicas, mas ao mesmo tempo como plasmadoras do ideário de forças políticas partícipes na fundação do país.

Dito isso, se bem as guerras civis argentinas se dão de forma prévia a uma geopolítica organizada enquanto disciplina, certo é que tal disputa local manifesta uma racional de enfrentamento entre uma ideia de organização territorial continentalista e outra centrada num enlace estratégico a uma potência além-mar. Tal dualidade avançou ao século XX, embora já racionalizada sobre conceitos estritamente geopolíticos advindos do norte global. Ao redor da obra de Segundo Storni, recorrendo a aquelas concepções mahanianas, mas primariamente apoitada no legado sarmientiano, estruturou-se uma racional de justificação a continuidade ao atrelamento subalterno a potência marítima do momento. Por sua vez, naquela aproximação geopolítica nacionalista soerguida na década de 1910, e que haveria de desaguar no Movimento Nacional Justicialista, aludiu-se a continuidade do legado mítico-cultural do bando federal com vistas postas as possibilidades da vastidão do hinterland continental e da teluricidade politica, próprios da geopolitik germânica, mas recorrendo reiteradamente a obra fundacional hernandiana.

Nesse sentido, cremos estar demonstrado que uma análise da Argentina desde sua fundação sob o prisma da batalha fundamental entre terra e mar cobra razões para além do estético, ainda tendo por diante que tal enfrentamento autóctone lastreado em racionais geo-políticas tão marcadamente enraizadas deixou marcas indeléveis no devir nacional. Afinal, ambas as correntes seguem em disputa na contemporaneidade, 
com vantagens a linha talassocrática, devindo ao fato de que as concepções territoriais da Argentina jamais pudessem encontrar um eixo de comunhão.

\section{REFERÊNCIAS BIBLIOGRÁFICAS}

Abeille, L. (1901). Idioma nacional de los argentinos: antinomia linguística indisoluble. Buenos Aires: Círculo Militar.

Alberdi, J. B. (1886). Obras Completas. Buenos Aires: Tribuna Nacional. (1913). Organización de la Confederación Argentina. Madrid: Baily.

Altamirano, C. (2001). Bajo el Siglo de las Masas. Buenos Aires: Ariel.

Astrada, C. (1948). El mito Gaucho: Marín Fierro y El Hombre Argentino. Buenos Aires: Cruz del Sur.

Borges, J. L. (1985). O Martín Fierro. Porto Alegre: L\&PM. . (1998). Prólogos con un prólogo de prólogos. Madrid: Alianza.

Aires: Emecé. (2007). Sarmiento. In: Borges, J. L. Textos recobrados (1956-1986). Buenos

Boyagoda, R. (2016). When Literary Politics Mattered to Geopolitics, American Literary History, Volume 28, 3. 634-643. Disponível em: https://academic.oup.com/alh/articleabstract/28/3/634/1740842

Cabral, F. (1970). No soy de aquí ni soy de allá. Vinil, 7". Odeon Pops.

Cabral, S. (2013). Artigas y la Patria Grande. Buenos Aires: Corregidor.

Canclini, N. G. (2001). Estrategias para entrar y salir de la modernidad. Buenos Aires: Paidós.

(2004). Diferentes, desiguales y desconectados: Mapas de la interculturalidad. Barcelona: Gedisa.

Cangiano, G. (2001). 'El pensamiento vivo de Arturo Jauretche', In: Cangiano, G. Nuevos Aportes sobre Arturo Jauretche. Buenos Aires: Archivo y Museo Históricos de la Provincia.

Casas, M. E. (2020). 'El Martín Fierro libertario. Problemáticas, resignificaciones y continuidades en las lecturas ácratas del poema durante la primera mitad del siglo XX', Páginas, 12(30). DOI: https://doi.org/10.35305/rp.v12i30.447. Disponível em: https://revistapaginas.unr.edu.ar/index.php/RevPaginas/article/view/447. 
Crocco, M. (1995). 'Epílogo al Martín Fierro y su Vuelta', Electroneurobiología, 2(1), p. 474-495.

Cutolo, V. O. (1978). Nuevo Diccionario Biográfico Argentino. Tomo V. Buenos Aires: Elche.

Dalle, P. (2008). 'La Nación imposible, la que somos y la anhelada. Reflexiones sobre la identidad nacional argentina', Revista Intersticios de Pensamiento Crítico, 2(1). Buenos Aires.

(2010). 'Estratificación social y movilidad en Argentina (1870-2010). Huellas de su conformación socio-histórica y significados de los cambios recientes', Revista de Trabajo, 6(8), Enero/Julio.

Deleuze, G; Guattari, F. (1995). Mil Platôs: Capitalismo e esquizofrenia, Vol. 2. São Paulo: Editora 34.

Donghi, T. H. (1994). 'Mitre e a formulação de uma história nacional para a Argentina', Estudos Avançados, 8(20), p. 199-214, São Paulo. Disponível em: https://www.scielo.br/scielo.php?script=sci arttext\&pid=S0103-40141994000100020.

Dugin, A. (1997). Osnovy geopolitiki: geopoliticheskoe budushchee Rossii. Moscou: Arktogeia.

Escolar, D. (2011). 'De montoneros a indios: Sarmiento y la producción del homo sacer argentino', Corpus, 1(2). Disponível em: https://journals.openedition.org/corpusarchivos/1132.

Evola, J. (1979). A Tradição Hermética. São Paulo: Edições 70.

Fávaro Martins, M. A. (2016). Terra e mar no pensamento geopolítico argentino: da disputa hegemônica no cenário doméstico a sua influência sobre a Geopolítica do Brasil. Tese de Doutorado: USP.

Ferré, M. (1961). 'Artigas o la esfinge criolla'. Semanário Marcha: Montevideo, № 1.058

Fontana, P. (2011). 'Sarmiento y sus monstruos biográficos', In: Dominguez, N. et. al. (Comps.) Miradas y saberes sobre lo monstruoso. Buenos Aires: Editorial de la Facultad de Filosofía y Letras de la Universidad de Buenos Aires.

Gálvez, M. (1945). José Hernández. Buenos Aires: Huemul.

Garré, N. C. (2009). 'Presentación - Actualidad del mensaje de Segundo Storni', In: Storni, S. R. Intereses argentinos en el mar. 4a Ed. Buenos Aires: Ministerio de Defensa.

Guglialmelli, J. E. (1979). Geopolítica del Cono Sur. Buenos Aires: El Cid.

Goyal, Y. (2017). 'Literature and Geopolitics', In: Goyal, Y. The Cambridge Companion to 
Transnational American Literature, pp. 219-268. Cambridge: Cambridge University Press.

Gullo, M. (2011). El país que soñó Sarmiento. Disponível em: https://www.marcelogullo.com/el-pais-que-sono-sarmiento/.

Howell, Y. (2016). 'A Clash of Fictions: Geopolitics in recent Russian and Ukrainian Literature', Japanese Slavic and East European Studies, vol. 37, p. 1-16. Disponível em: https://www.jstage.jst.go.jp/article/jsees/37/0/37 1/ article/-char/en.

Jauretche, A. M. (1968). Manual De zonceras argentinas. Buenos Aires: Peña Lillo.

Kaplan, R. D. (2014). Literature and Geopolitics. Disponível em: https://worldview.stratfor.com/article/literature-and-geopolitics.

Hernández, J. (1944). Prosas y Oratória Parlamentaria. Buenos Aires: Futuro. (2009). Martin Fierro. Buenos Aires: RTM.

Ludmer, J. (2002). O gênero gauchesco: um tratado sobre a pátria. Chapecó: Argos.

Mármol, J. (1889). 'A Rosas', In: Mármol, J. Obras de José Mármol. Cantos del Peregrino: Poesías Diversas.

Mello, L. I. A. (1999). Quem tem medo da Geopolítica. São Paulo: EDUSP.

Minelli, I. (2010). A força política na grandeza das formas: o século XIX em diálogo nas obras de Sarmiento e Hernández. Tese de doutorado. Campinas: UNICAMP.

(2013). 'Sarmiento e Hernández em diálogo: o universo da literatura gauchesca e o embate dos saberes no século XIX argentino', Revista Contemporânea, Dossiê História e Literatura, $n^{\circ} 4$.

Moniz Bandeira, L. A. (2004). Argentina, Brasil y Estados Unidos. De la Triple Alianza al Mercosur. Buenos Aires: Norma.

Monteiro, N. S. (2013). 'Mahan - 7 Virtudes e 7 Pecados', Cadernos Navais, no 45, AbrilJunho. Lisboa: Edições Culturais da Marinha.

Nad, B. (2016). 'The East and the West', The Fourth Political Theory. Disponivel em: http://4pt.su/en/content/east-and-west.

Lillo, A. (2018). 'La literatura de ficción como fuente histórica', Studia Historica: Historia Contemporánea, vol. 35, p. 267-288. Disponível em: https://revistas.usal.es/index.php/0213-2087/article/view/17981.

Pedraza, L. D. (2009). Realismo-Sistémico-Estructural: La política exterior como "Construcción" de Poder. Córdoba: Edición del Autor. 
Pickenhayn, J. A. (2000). 'Scripta Nova', Revista Electrónica de Geografía y Ciencias Sociales, no 62. Universidad de Barcelona.

Quattrocchi-Woisson, D. (1995). Los males de la memoria: história y política en la Argentina. Buenos Aires: Emecé.

Quintero, S. (1999). 'El país que nos contaron: la visión de Argentina en los manuales de geografía (1950-1997)', Entrepasados, no 16. Buenos Aires.

Ramos, J. (1989). Desencuentros de la modernidad en América Latina: literatura y política en el siglo XIX. México: Fondo de Cultura Económica.

Rizzo Romano, A. H. (1973). Bases para uma Geopolítica Argentina. Buenos Aires: Las XII Tablas.

Sarmiento, D. F. (1999). Facundo o civilización y barbarie en las pampas argentinas. Buenos Aires: El Aleph.

. (2000). Argirópolis. Buenos Aires: El Aleph.

(2010). El Chacho, último caudillo de la Montonera de Los Llanos: Episodio de 1863. Buenos Aires: Biblioteca Quiroga Sarmiento.

Schmitt, C. (1942). Land und Meer. Eine weltgeschichtliche Betrachtung. Leipzig: Verlag von Philipp Reclam.

Seixlack, A. G. C. (2012). 'Julio Argentino Roca: um projeto de Nação Argentina', Anais Eletrônicos do X Encontro Internacional da ANPHLAC. São Paulo. Disponível em: http://anphlac.fflch.usp.br/sites/anphlac.fflch.usp.br/files/alessandra seixlack2012.pdf.

Shumway, N. (2008). A invenção da Argentina: História de uma ideia. São Paulo: EDUSP.

Suárez, N. (2018). 'La pampa en movimiento: figuraciones del paisaje del Martín Fierro de José Hernández al filme Nobleza gauch', Anclajes, vol. XXII, nº 1, p. 73-94.

Trias, V. (1975). 'El Paraguay de Francia El Supremo a La Guerra De La Triple Alianza', Cuaderno de Crisis, no 19.

. (1978). 'Iberoamérica: Balcanización, Integración dependiente e Integración liberadora', Nueva Sociedad, no 37, Julio-Agosto.

Ullivarri, J. E. D. (2005). 'Don Quijote y la Celestina en la pampa de Martín Fierro', Hispanista, no 20.

Unamuno, M. (1996). Unamuno a Casimiro Muñoz, abril de 1899. Madrid: Epistolário Americano. 